\title{
SUNSPOT MOTION, FLARES AND TYPE III \\ BURSTS IN McMATH 11482
}

\author{
H. ZIRIN and B. LAZAREFF* \\ Big Bear Solar Observatory, Hale Observatories, Carnegie Institution of Washington, California In- \\ stitute of Technology, U.S.A.
}

(Received 9 May, 1973; in revised form 24 October, 1974)

\begin{abstract}
We have studied a series of flares in McMath 11482, 1972 August 19-22, with particular reference to the basis for the flares and comparison with dekameter radio data. We find that the flares were produced by rapid $\left(\sim 1000 \mathrm{~km} \mathrm{~h}^{-1}\right)$ westward motion of a large new $p$ spot. Many fiares occur just in front of the spot, and they cease when the motion stops. All flares occurring in front of the spot produce type III bursts, while even strong flares elsewhere in the region produce little or no type III. The time of type III emission agrees perfectly with the start of the $\mathrm{H} \alpha$ flare. Thus type III bursts are only produced in favorable configurations.

Simultaneous K-line movies are compared with $\mathrm{H} \alpha$ films and show little difference in flare appearance.
\end{abstract}

\section{Introduction}

We have studied the evolution of the large active region McMath 11482, that crossed the disk in 1972 August, with particular attention to the types of radio emission produced by different flares and to the connection of a number of flares with rapid sunspot motion in a newly emerging spot. We propose a mechanism by which the motion of this spot produces crossing of transverse magnetic fields (referred to as fibril crossing). There appears to be some relation between the location of flares and the production of type III radio bursts. We have carefully compared our optical flare observations with sensitive swept frequency radio records from the University of Colorado (kindly furnished by Prof. J. W. Warwick) which show even very weak bursts in the $7-40 \mathrm{MHz}$ range. Almost all flares occurring in front of the moving spot produced strong type III bursts while comparable $\mathrm{H} \alpha$ events elsewhere in the region produced no type III emission. The flares producing type III bursts were all accompanied by surges and outward eruptions; and their radio spectra all increase to long wavelength. We compared the movies made simultaneously in $\mathrm{H} \alpha$ and the $\mathrm{K}$-line; no substantial difference between the $\mathrm{H} \alpha$ and $\mathrm{K}$-line appearance of flares was seen.

\section{History of the Group}

McMath 11445 was born at the same Carrington position on the preceding rotation but remained small and quiet. McMath 11482 appeared on the east limb on August 17 as a large new bipolar group, with a $p$ spot followed by a bright plage. Most of the activity took place between the 19th and 22nd of August, although there was a later

*Present address: Radioastronomie, Observatoire de Meudon, 92190 Meudon, France. 


\section{BIG BEAR SOLAR OBSERVATORY \\ ACTIVE REGION DEVELOPMENT}

AUGUST 18-23, 1971

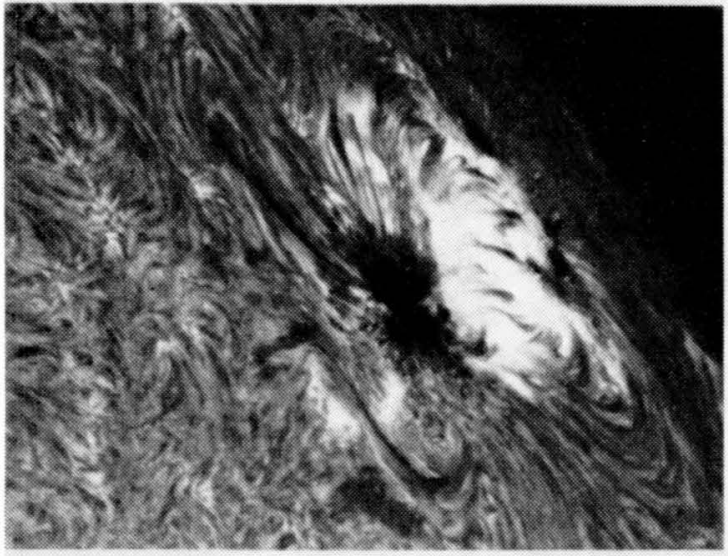

$3 / 18 \quad 19: 12: 57$

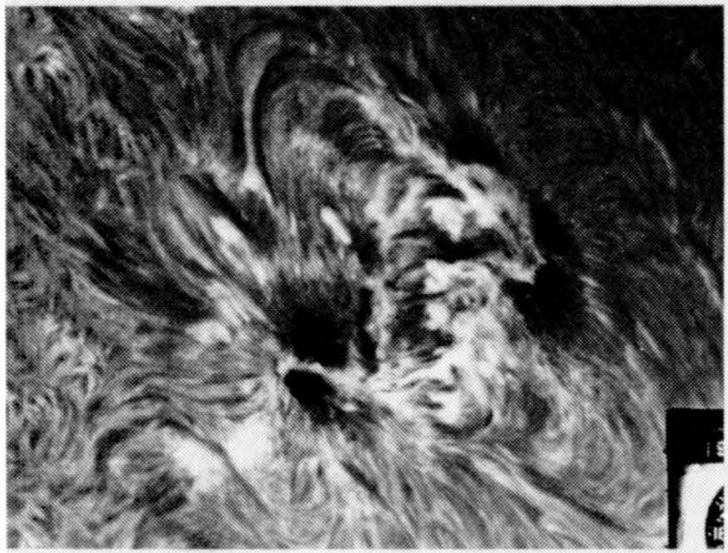

$8 / 19 \quad 19: 55: 56$

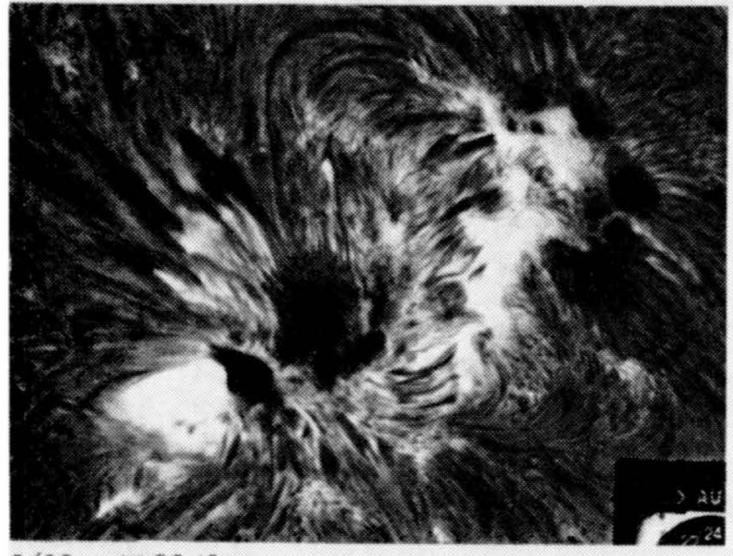

$8 / 20 \quad 17: 22: 16$

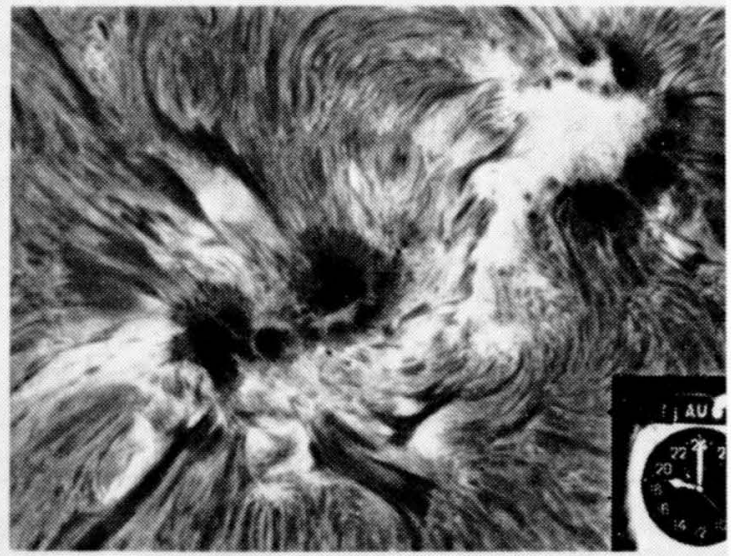

$8 / 21 \quad 19: 00: 23$

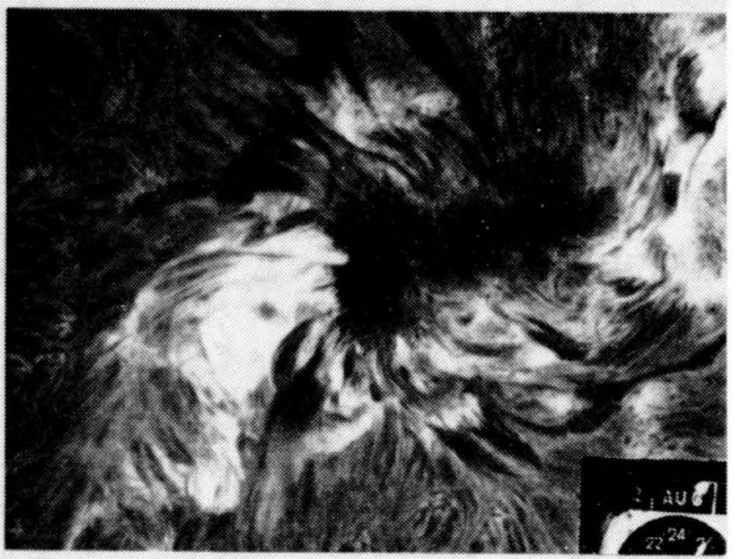

$8 / 22 \quad 20: 06: 24$

e

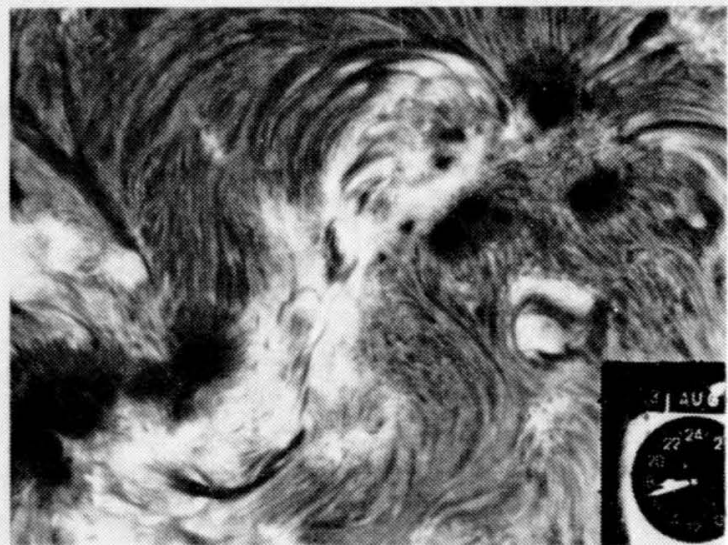

$8 / 23 \quad 17: 42: 25$

Fig. 1. A sequence of $\mathbf{H} \alpha$ prints, $8 / 18$ to $8 / 23$, showing the development of the region. Flares are shown on the $8 / 20$ and $8 / 22$ prints. Note how the long train of sunspots follows the lead spot forward. W - left, S - top on all photos. 
resurgence of activity at west limb passage on the 30th, followed by a proton flare September 1. Figure 1 shows the development of the group in $\mathrm{H} \alpha$ August 18-23, while Figure 2 shows a sketch of the sunspots in the critical period August 20-22. Table I shows the number of flares on each day (listed in this region by Solar-Geophysical Data) showing graphically the activity between the 19th and 24th. The flares up to the 23rd took place mainly in the $p$ part of the group, while those after this time took place in the following half. Except for Table I, we refer only to Big Bear data, which was interrupted by clouds on some days.
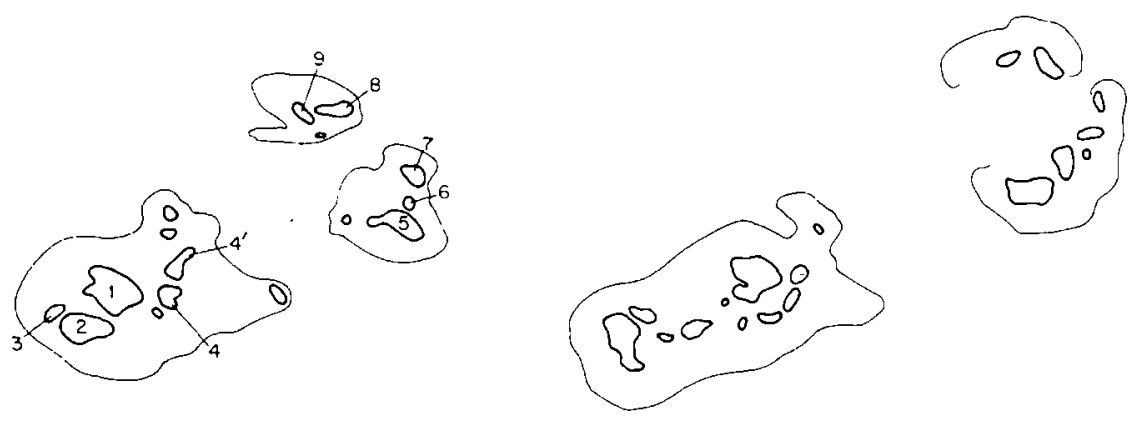

AUG20@0:00
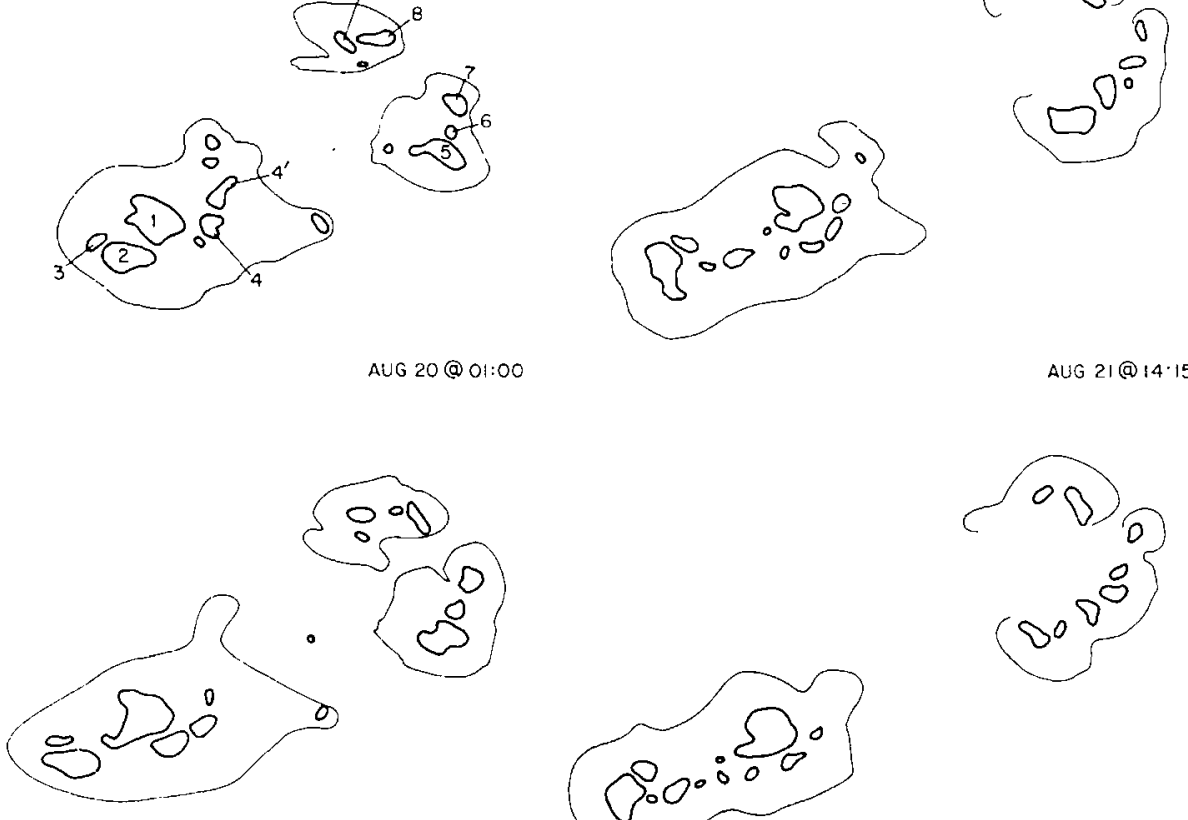

AUG 20@14:30
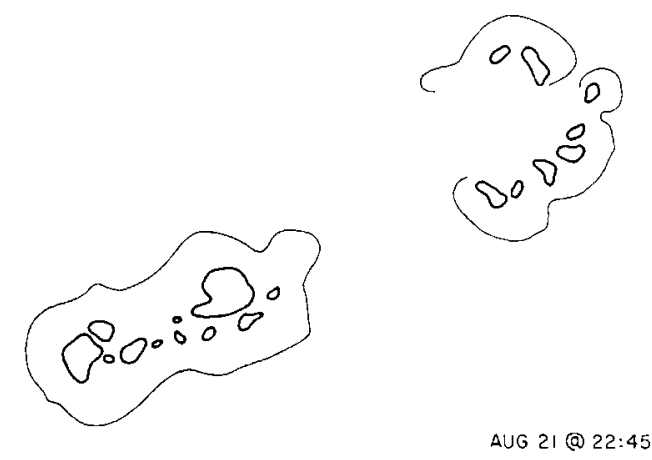

AUG 2I@:4.15
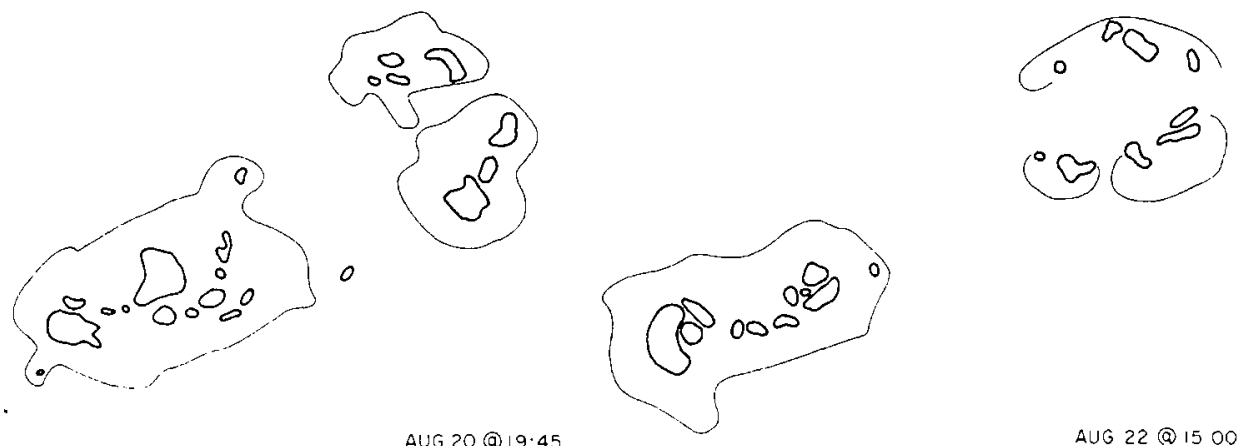

AUG 20 @19.45

Fig. 2. Drawings of the sunspots (based on $\mathrm{H} \alpha$ off-band pictures) during the critical period, August 20 to 22 ; the spots are all numbered in the first drawing.

TABLE I

Outline of activity in McMath 11482

\begin{tabular}{lrrrrrrrrrr}
\hline Day (August) & 18 & 19 & 20 & 21 & 22 & 23 & 24 & 25 & 26 & 27 \\
H $\alpha$ events & 5 & 17 & 27 & 31 & 32 & 23 & 15 & 5 & 11 & 14 \\
X-ray events & 3 & 2 & 4 & 1 & 4 & 2 & 1 & 1 & 0 & 1 \\
\hline
\end{tabular}


The region appeared on the limb in bipolar form, with a bright $\mathrm{H} \alpha$ plage following and a dominant $p$ spot; off-band photos showed many Ellerman bombs, indicators of new emerging flux. The main spot on the 17th; on the 18th the northern part of the region was covered by an intense emerging flux region (EFR), the $p$ spot of which grew rapidly and moved forward around the old $p$ spot. A substantial flare filled the EFR at 23:43 on the 18th, producing a type III burst. By sunset on the 18th the new spot (marked 2 in Figure 2) was already large. It was the $p$ part of a large new dipole emerging on the north side of the region.

\section{Developments August 19}

On the 19th spot 2 had moved rapidly forward, while spot 1 did not move at all relative to the following spots. The drawings in Figure 2 show the relative orientation of the spots. On the 19th, spot 2 was just below (north of) spot 1. On the 20th at 01:00 (see Figure 2) spots 2 and 3 had moved slightly west, and the motion of spot 2 continued at least until the 21st at 15:30. Note how:

- spot 3 apparently was pushed aside and back of spot 2 by the flow;

- spots 4, 4', etc. followed behind spot 2 and past spot 1 ;

- spot 1 was sheared (20th at 14:30) and torn away later apparently by the material being drawn past it.

The motion of spot 2 was due west, with velocities as follows:

19th at $18: 30-20$ th at $15: 15 \quad 1100 \mathrm{~km} \mathrm{~h}^{-1}$

20th at 15:15-21st at $01: 15 \quad 1500 \mathrm{~km} \mathrm{~h}^{-1}$

21st at $01: 15-21$ st at $15: 30 \quad 750 \mathrm{~km} \mathrm{~h}^{-1}$.

After the 21st at 15:30, spot 2 did not move appreciably, but spot 4 continued its motion (see 21st at 22:45) and ended up against spots 2 and 3, while spot 1 began to break up.

Although the X-ray flares on the 18th and 19th occurred in the middle of the EFR, while the rapid motion of spot 2 took place, almost all flares in the region occurred either just preceding it or around it. Furthermore, all type III bursts came from this region. There was a very bright, continuously active place at the front (west) edge of the spot 2, out of which all these flares grew and blew off to the west.

\section{The Flares of August 20 and 21}

By the 20th (Figures 1 and 2), the new $p$ spot (2) was as large as the old (1) and had moved around ahead of it. A bright rim on the edge of the new spot was the source of a series of flares which were particularly prolific in producing type III bursts. Presumably, the occurrence of these flares was due to the motion of the new spot 2 and bunching and twisting of field lines produced by this motion, as shall be explained below. Most of these flares produced great surges and eruptions following arched field lines connecting ahead of the group to $f$ polarity just outside the frame. Further all the flares came from the edge of the umbra; no emission was ever seen over the 

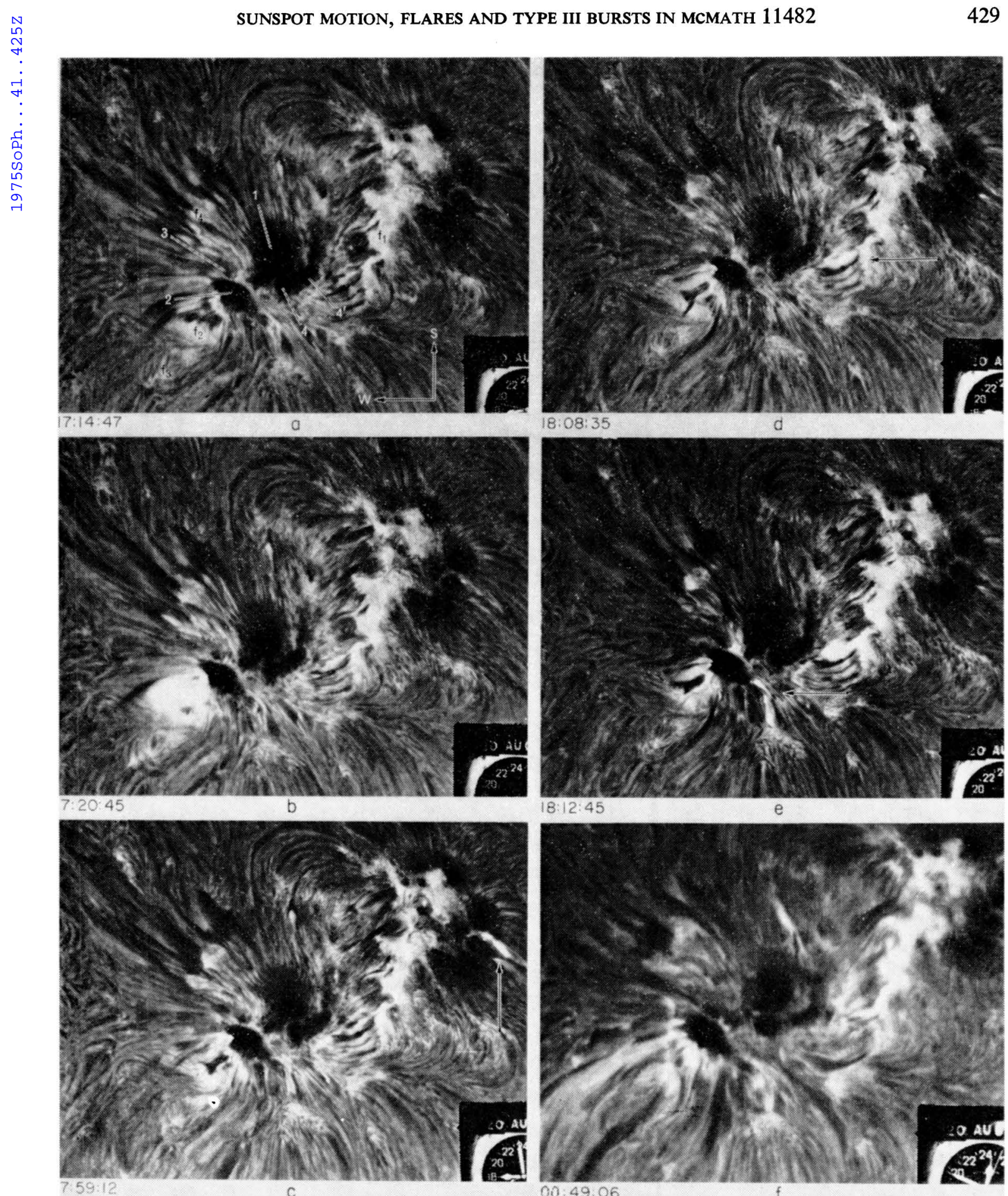

Fig. 3. A series of prints of events on August 20. In (a) the different plages and spots are marked, in (b) a bright surge, and in (c), (d), (e) a series of small brightenings sweeping across the region and leading to the flare of Figure $4 ; f$ shows a bright surge on August 21.

umbra, although it could have easily been detected if present. In several cases material could be seen returning very rapidly, while outflow still took place.

The Mount Wilson magnetogram on the 19th shows a plage of $f$ polarity just west of spot 2 with a field between 10 and and 20 gauss, and a steep gradient between them. 

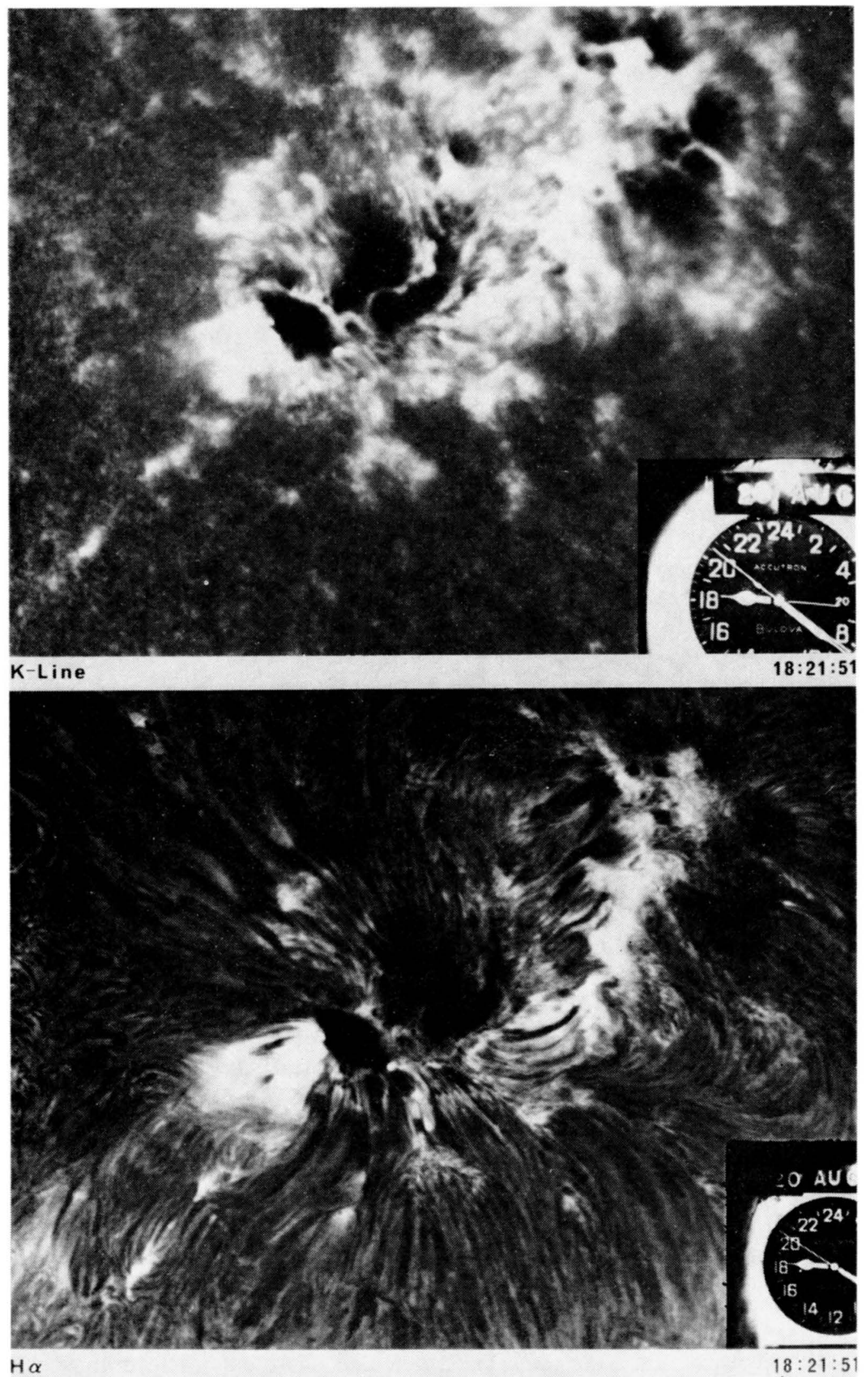

Fig. 4. Simultaneous $\mathrm{H} \alpha$ and $\mathrm{K}$-line (1.2 $\AA$ bandwidths) pictures of the $18: 22$ flare. If the $\mathrm{K}$ filter is set at $0.3 \AA$, dark fibrils may be seen, but the exposures become very long. Note the bright areas at lower left produced by dumping of flare particles. These areas brighten simultaneously with the flare beginning and are probably excited by fast electons or a shock wave. 
In the absence of higher resolution magnetic observations, we identify this with the plage $f_{2}$ just W (left) of spot 2 (Figure $3 \mathrm{a}$ ), connected to it by short dark fibrils. This is, of course, characteristic of newly emerging flux, and may either be flux accumulated by the motion of the spot, or reentering field lines from the spot being overrun by the rapidly moving sunspot 2 .

On August 20 a sequence of flares triggered by the same disturbance was seen (Figure 3c, d, e). We saw:

(1) a small flare in the following half of the group at 17:59 (arrow, Figure 3c),

(2) a bright flare in the FTA region, starting 18:08 (arrow, Figure 3d),

(3) a small brightening NE of spot 2 at 18:12 (arrow, Figure 3e),

(4) a bright flare $\mathrm{W}$ of spot 2 starting at 18:14 and quite similar to the flare surge at $17: 22$.

The last is the flare shown in $\mathrm{H} \alpha$ and $\mathrm{K}$ in Figure 4. It produced a continuous long dark surge, which is shown in Figure 5 to the blue of $\mathrm{H} \alpha$. Although the surge only appeared to move around $100 \mathrm{~km} \mathrm{~s}^{-1}$, waves of brightness variation are seen to move

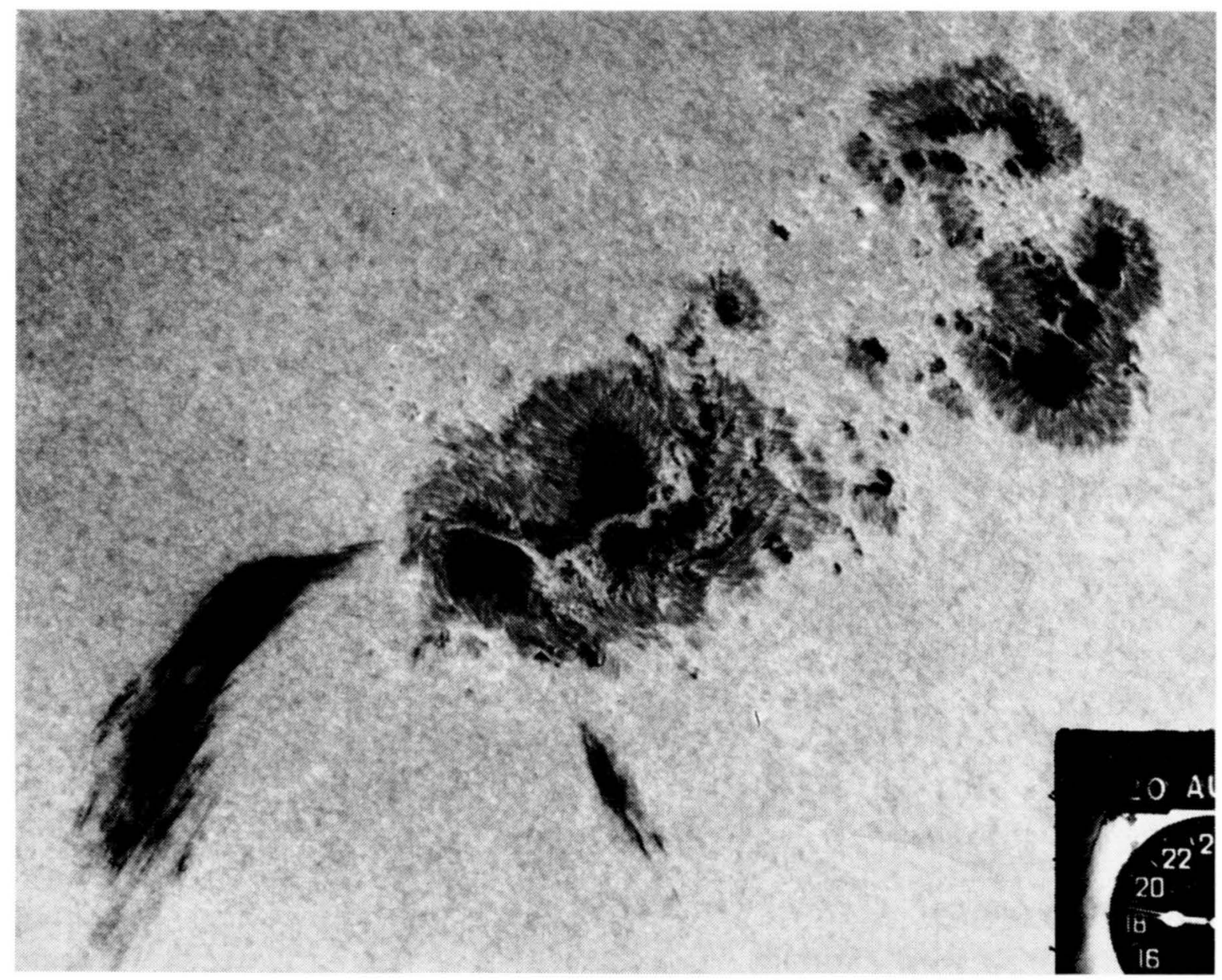

Fig. 5. Photo at $\mathrm{H} \alpha-2 \AA, 18: 25: 45$ UT, $8 / 20$. The main surge is nicely visible thanks to its Doppler shift; and a smaller simultaneous surge to the north (below) is also seen. A number of Ellerman bombs are seen in various places. Note the sharply sheared penumbral structure along spot 2 and in the area of the 18:08 flare. Such sheared penumbrae, with fibrils parallel to the edge of the umbra rather than radial, are typical flare-producing structures and presumably caused by the spot motion. 
outward even more rapidly through the surge. Also, two bright areas appeared in the chromosphere to the west of the surge; the time delay corresponds to a wave of excitation moving out at $500 \mathrm{~km} \mathrm{~s}^{-1}$. Surprisingly, within a minute after the start of the flare, material began moving rapidly inwards along the surge while other matter was still flowing rapidly outward. This again would require at least $500 \mathrm{~km} \mathrm{~s}^{-1}$ to communicate the start of the flare. The time and distance spacing in the sequence leading to the 18:14 flare are consistent with the propagation of a disturbance (not visible in $\mathrm{H} \alpha$ ) travelling at $160 \mathrm{~km} \mathrm{~s}^{-1}$, and becoming a $500 \mathrm{~km} \mathrm{~s}^{-1}$ wave as it travels out. The $a$ priori probabiliy of such a sequence is small, and we think that the phenomenon is real.

On August 20, we observed at Big Bear, fifteen brightenings or flares in front of spot 2, all of which produced type III bursts, twelve of which were intensity 2 or 3 . There were four flares in other places in the spot group, which produced one burst of imp 2 at $22: 21$, and only very weak bursts otherwise.

Although the flares ahead of spot 2 were obviously the largest, we found type III bursts connected with even very weak brightenings there, whereas none of the flares in the other parts of the region produced bursts. It would appear from this that containment is not the principal factor, but that the region in front of the spot 2 was very favorably situated for the acceleration and emission of the electrons responsible for type III bursts. The times of the type III bursts invariably agreed (to within $15 \mathrm{~s}$ ) with the times of the $\mathrm{H} \alpha$ flashes (steepest rise), implying that the energetic electrons are produced right at the start, and that the $\mathrm{H} \alpha$, which lasts 5 or 10 minutes longer, represents the later evolution. Such a type III dekameter productive region near the main spot was found by Zirin and Werner (1967).

By the 21st, the spot 2 had moved about $15000 \mathrm{~km}$ ahead of spot 1, and flares continued from the west edge of the spot. We observed at least ten similar small flares at this point, all of which produced intense type III bursts, along with no soft X-rays, and slight $\mathrm{cm}$ emission. Again, various flares at other points in the region produced soft X-rays or cm emission, but no type III bursts. Figure 6 shows 2 flares, one at $16: 26: 12$ in the unfavorable region south of spot 2 , which gave no type III, the other at 18:21:07 in front of spot 2, which gave a big type III burst.

Table II lists most of the flares and bright surges observed August 19, 20, and 21 at Big Bear. The only omissions are small brightenings outside the most active area that did not produce type III bursts. All strong dekameter type III are listed. A noise storm after August 21 prevented further identification except for a few cases. Comparison with radio data rapidly showed that a strong correspondence between dekameter bursts and surges coming from the area preceding spot 2. Almost every strong type III on the Boulder records (kindly furnished by Prof. J. W. Warwick) showed a corresponding brightening preceding spot 2; examination of the table shows this. On the other hand, larger flares in other parts of the region showed no dekameter. Comparison with meter bursts shows no clear correspondence with brightenings, no matter where. There is so much optical and radio activity in a large region like this that time correspondence is usually very difficult; but the correspondence of dekameter bursts and brightenings preceding spot 2 is easy and clear. 


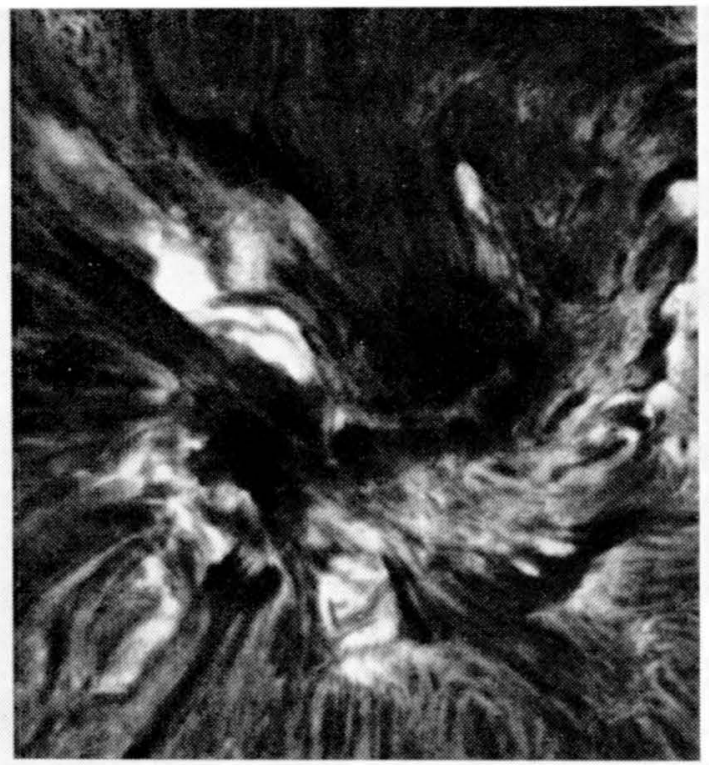

$8 / 21$

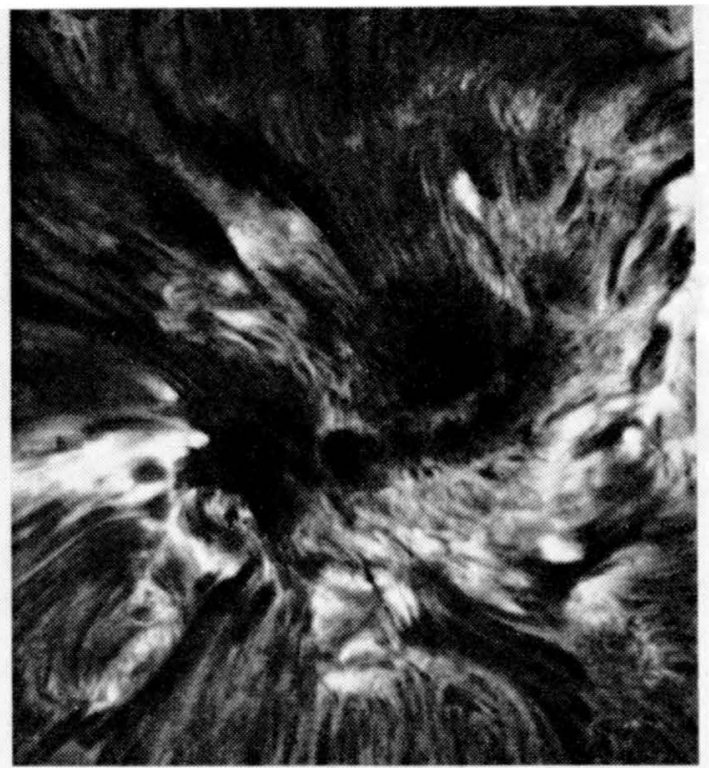

$8 / 21$

$18: 21: 07$

Fig. 6. Two flares on August $21 ; 16: 26: 12$, wrong place, no type $111 ; 18: 21: 07$, right place, large type III.

TABLE II

Flares observed at Big Bear

\begin{tabular}{|c|c|c|c|c|c|c|}
\hline Time & Place & Type & $\begin{array}{l}\text { X-rays } \\
\left(\mathrm{erg} \mathrm{cm}^{-2} \mathrm{~s}^{-1}\right)\end{array}$ & $\begin{array}{l}\text { Iono- } \\
\text { sphere }\end{array}$ & $\begin{array}{l}\mathrm{cm} \\
(\mathrm{MHz})\end{array}$ & $\begin{array}{l}\text { Dekameter } \\
\text { (imp.) }\end{array}$ \\
\hline \multicolumn{7}{|c|}{ August 19} \\
\hline 1600 & f2 & contained & $6 \times 10^{-3}$ & SPA & $\begin{array}{l}7.4 \mathrm{sfu} \\
(9000)\end{array}$ & - \\
\hline 1715 & $\mathrm{p} 2$ & $\begin{array}{l}\text { eruption, } \\
\text { not brt. }\end{array}$ & $-0-$ & SID & - & IIIGG (3) \\
\hline 1835 & f 2 & contained & 3.5 & SFD & - & - \\
\hline \multicolumn{7}{|c|}{ August 20} \\
\hline 0010 & $\mathrm{p} 2$ & $\begin{array}{l}\text { small, brt. } \\
\text { surge }\end{array}$ & -0 & SFD & - & IIIG (2) \\
\hline 0126 & S1 & $\begin{array}{l}\text { v. fast, low } \\
\text { brt. surge }\end{array}$ & No obs. & - & - & - \\
\hline 1703 & $\mathrm{p} 2$ & brt. surge & -0 & SFD & - & IIIGG (1) \\
\hline 1716 & p2 & big, brt. surge & 9 & - & - & III (3) \\
\hline 1806 & $\begin{array}{l}\text { f } 1 \\
\text { (mid. } \\
\text { of } \\
\text { group) }\end{array}$ & $\begin{array}{l}\text { tight, } \\
\text { contained }\end{array}$ & 2 & SFD & - & III (1) \\
\hline 1818 & $\mathrm{p} 2$ & big, brt. surge & 4 & SFD & - & IIIG (3) \\
\hline 1943 & p2 & big, brt. surge & No obs. & SPA & - & IIIG (3) \\
\hline 2032 & $\mathrm{p} 2$ & $\begin{array}{l}\text { big, brt. } \\
\text { surge }\end{array}$ & No obs. & SES & - & III (3) \\
\hline 2106 & S1 & $\begin{array}{l}\text { big, brt. } \\
\text { surge }\end{array}$ & No obs. & - & - & - \\
\hline 2153 & $\mathrm{p} 2$ & $\begin{array}{l}\text { big, brt. } \\
\text { surge }\end{array}$ & 2 & SFD & $\begin{array}{l}2.8 \mathrm{sfu} \\
(2800)\end{array}$ & III (3) \\
\hline
\end{tabular}


Table II (Continued)

\begin{tabular}{|c|c|c|c|c|c|c|}
\hline Time & Place & Type & $\begin{array}{l}\text { X-rays } \\
\left(\mathrm{erg} \mathrm{cm}^{-2} \mathrm{~s}^{-1}\right)\end{array}$ & $\begin{array}{l}\text { lono- } \\
\text { sphere }\end{array}$ & $\begin{array}{l}\mathrm{cm} \\
(\mathrm{MHz})\end{array}$ & $\begin{array}{l}\text { Dekameter } \\
\text { (imp.) }\end{array}$ \\
\hline 2221 & & $\begin{array}{l}\text { same as } \\
2106, \text { smller }\end{array}$ & $-0-$ & - & - & - \\
\hline 2240 & $\mathrm{p} 2$ & brt. surge & No obs. & - & - & - \\
\hline \multicolumn{7}{|c|}{ August 21} \\
\hline 1405 & $\mathrm{p} 2$ & $\begin{array}{l}\text { brt. long- } \\
\text { lived surge }\end{array}$ & $2 \times 10^{-3}$ & SES & - & IIIGG (2) \\
\hline 1444 & Nf5 & $\begin{array}{l}\text { small, brt. } \\
\text { no motion }\end{array}$ & $-0-$ & - & $\begin{array}{l}4.6 \mathrm{sfu} \\
(8800)\end{array}$ & - \\
\hline 1505 & p9 & $\begin{array}{l}\text { small, brt. } \\
\text { no motion }\end{array}$ & No obs. & - & - & - \\
\hline 1528 & S1 & $\begin{array}{l}\text { v. fast, } \\
\text { no motion }\end{array}$ & $-0-$ & - & - & - \\
\hline 1618 & $\mathrm{p} 2$ & brt. surge & 1 & - & - & - \\
\hline 1624 & $\mathrm{~S} 1$ & $\begin{array}{l}\text { complex } \\
\text { surge }\end{array}$ & 1 & - & - & - \\
\hline 1706 & $\mathrm{p} 2$ & faint surge & $-0-$ & - & - & IIIG (3) \\
\hline 1713 & p2 & faint surge & -0 & - & - & IIIG (3) \\
\hline 1745 & $\mathrm{p} 2$ & $\begin{array}{l}\text { fainter } \\
\text { than above }\end{array}$ & 2 & - & $\begin{array}{l}6.7 \mathrm{sfu} \\
(8800)\end{array}$ & IIIGG (3) \\
\hline 1819 & \multicolumn{6}{|c|}{ same as 1405} \\
\hline 1850 & $\mathrm{p} 2$ & $\begin{array}{l}2 \text { simult. } \\
\text { brt. surges }\end{array}$ & -0 & - & - & IIIGG (3) \\
\hline 1901 & $\mathrm{p} 2$ & $\begin{array}{l}\text { resurgence } \\
\text { of } \mathrm{p} 2\end{array}$ & $-0-$ & - & $\begin{array}{l}8.4 \mathrm{sfu} \\
(2800)\end{array}$ & III (3) \\
\hline 1925 & repeat & & & & & \\
\hline 1934.5 & \multicolumn{3}{|c|}{ same as 1405} & - & - & IIIG $(1+)$ \\
\hline 2030 & $\mathrm{p} 2$ & brt. surge & $-0-$ & - & - & - \\
\hline 2044 & $\mathrm{~N} 2$ & $\begin{array}{l}\text { fast, brt. } \\
\text { surge }\end{array}$ & & - & - & III (1) \\
\hline 2120 & S1 & flare erupt. & & - & $\begin{array}{l}9.2 \mathrm{sfu} \\
(9400)\end{array}$ & $\begin{array}{l}\text { in noise } \\
\text { storm }\end{array}$ \\
\hline 2125 & $\mathrm{p} 2$ & fast, small & & & 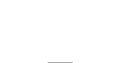 & 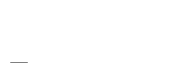 \\
\hline 2337 & N2 & complex flare & & SES & - & III (1) \\
\hline
\end{tabular}

Note: $\mathrm{p} 2$ means preceding spot $2 ; \mathrm{N} 1$ or $\mathrm{S} 1$ means north or south of spot (1).

\section{Fibril Crossings and Flares}

The flares in front of spot 2 all occur in regions of crossed fibrils, and several (e.g. Figure 1e) are seen to brighten simultaneously in two crossed fibrils. One connects spot 2 with the small $f$ polarity inclusion ahead of it and the other, also starts from spot 2 , but reconnects much farther, and crosses the first at a right angle. Although it is not clear from the $\mathrm{H} \alpha$ picture, we assume that the second fibril goes over the first. We suggest the following mechanism to create such a configuration:

When a sunspot, such as 2 , plows its way through the photosphere at a velocity of $1000 \mathrm{~km} \mathrm{~h}^{-1}$, the ram pressure $\varrho \cdot v^{2}$ at the base of the chromosphere is $16 \mathrm{dyne} / \mathrm{cm}^{-2}$, 
which is the magnetic pressure corresponding to a field of $20 \mathrm{~g}$. Going down a few scale heights, much stronger fields can be pushed around by the fluid motion. Let us now suppose that the sunspot is connected to nearby small inclusions of opposite polarity. As may be seen in Figure 7, the difference in angular velocity at these points results in crossing and twisting of the lines of force coming out of the sunspot. The sweeping up of field lines ahead of the spot and the subsequent reconnection of these lines of force leads to lower energy configurations.
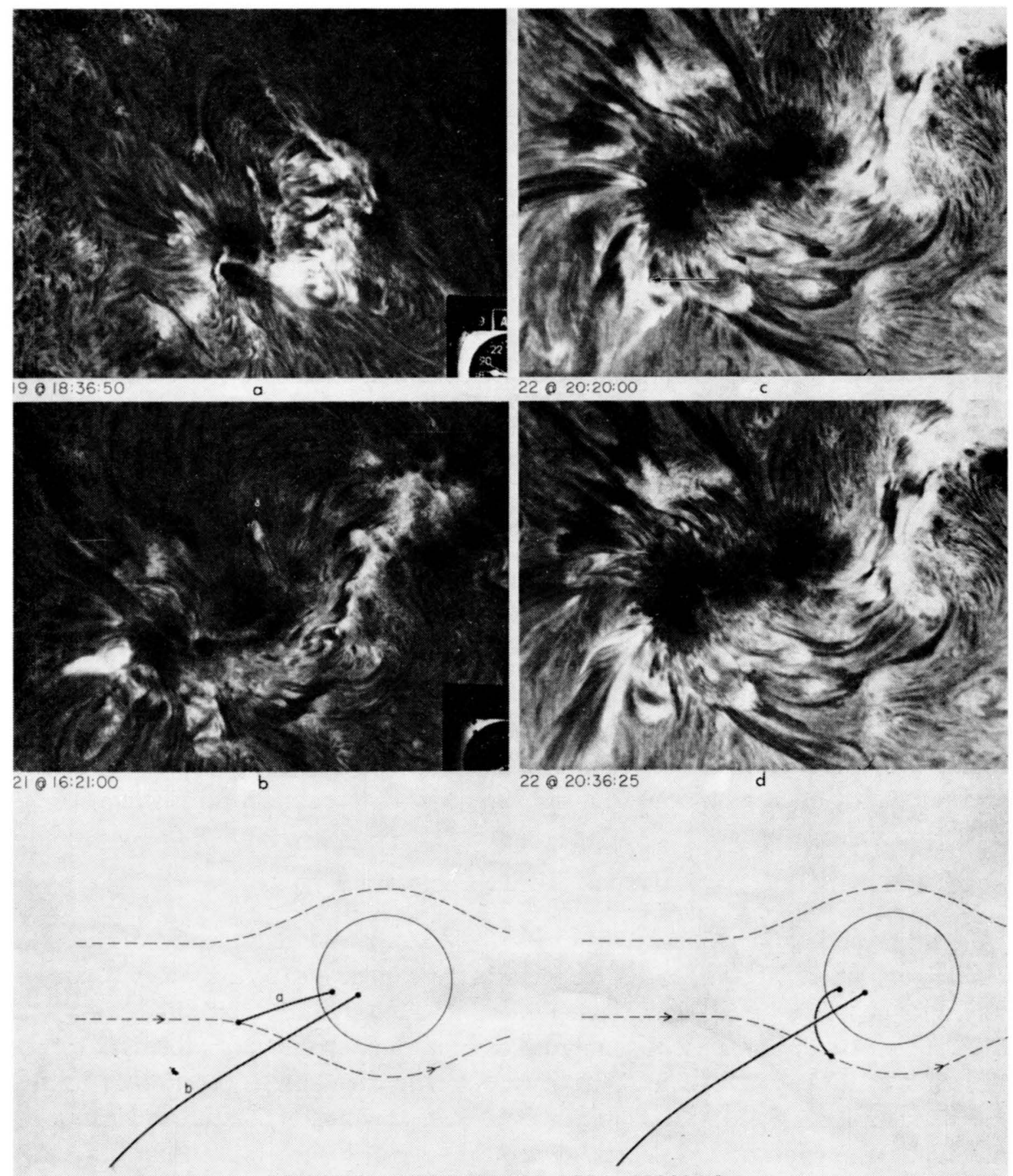

PROPOSED MECHANISM FOR FIBRIL CROSSING

Fig. 7. Illustrations of fibril crossing, and a sketch of the model. 
Another example of fibril crossing is given in Figure 7c, $d$ on the 22nd at 20:20:00. A flare starts at $20: 22$, with a brightening of the region shown by the arrow and helical uncoiling motions. The final situation is shown at $20: 36: 25$. An earlier flare $(20: 06: 24$, Figure 1e) shows the twisted fibrils in the erupting flare. It shows:

- a large fan of escaping field lines providing a wide path for the escape of hot plasma into the corona (there was a type III burst),

- a more direct connection of magnetic field lines than before the flare.

Crossed fibrils as a possible location for flares are mentioned by Severny (1960). We have found them to be commonly connected with flare occurrence. Much of the field twisting in this case occurred in the small area just ahead of spot 2; the examples we show are the outer, scaled-up manifestation of what was taking place right in the penumbra. Most of the surges showed fibril untwisting as the material flowed out.

\section{Subsequent Activity}

In the succeeding days, activity decreased in the $p$ part of 11482 , but flares began to occur in the extreme following part. Yet the general rule continued to hold that even small flares in the $p$ part gave sizeable type III while bright flares in the following part gave none. For example, a brilliant flash on the 25th at 19:22:20 gave an SFD, indicating hard X-rays. No radio was reported, not even at decimeter wavelengths (probably an observational problem). But quite small brightenings with outward surging at 23:02 and 23:46 ahead of the $p$ spot at 14:59 gave both $\mathrm{cm}$ and strong type III. The radio records for that event have appeared in Solar-Geophysical Data; the burst coincides with the $\mathrm{H} \alpha$ flash, which precedes the eruption by a few minutes - thus the electrons are accelerated in conjunction with the $\mathrm{H} \alpha$ flash, and do not escape just because of the eruption.

Finally, Figure 8 shows a handsome limb flare on August 30; it was a slow, low energy event, giving no radio emission and only soft X-rays. On the films we see strands of emission untwisting as the prominence rises; some of this may be seen in the second and third frames of Figure 1. Several strands appear to twist about one another. Many of the eruptions (but not the surges) show similar untwisting.

\section{H $\alpha$ and K-Line Comparison}

During this period one 10 -in. refractor fed a $\frac{1}{4} \AA$ Zeiss filter and the second, a $0.3 \AA$ Hale $\mathrm{K}$-line filter. Most of the $\mathrm{K}$-line pictures were made at $0.6 \AA$ or $1.2 \AA$ bandpass to reduce exposure time. We examined the simultaneous films to get similarities and differences. All flares appeared simultaneous in both lines; however, the dark surges were not easily seen in K-line. Obviously, since the structure is determined by the magnetic field, every $\mathrm{K}$-line feature has some corresponding $\mathrm{H} \alpha$ feature, and the only difference is in contrast and degree. As can be seen in Figure 4, dark fibrils are not easily seen in $\mathrm{K}$, partly because they have narrow absorption profiles and are not seen in $1.2 \AA$ bandpass and partly because they are doubly ionized and have low opacity. 

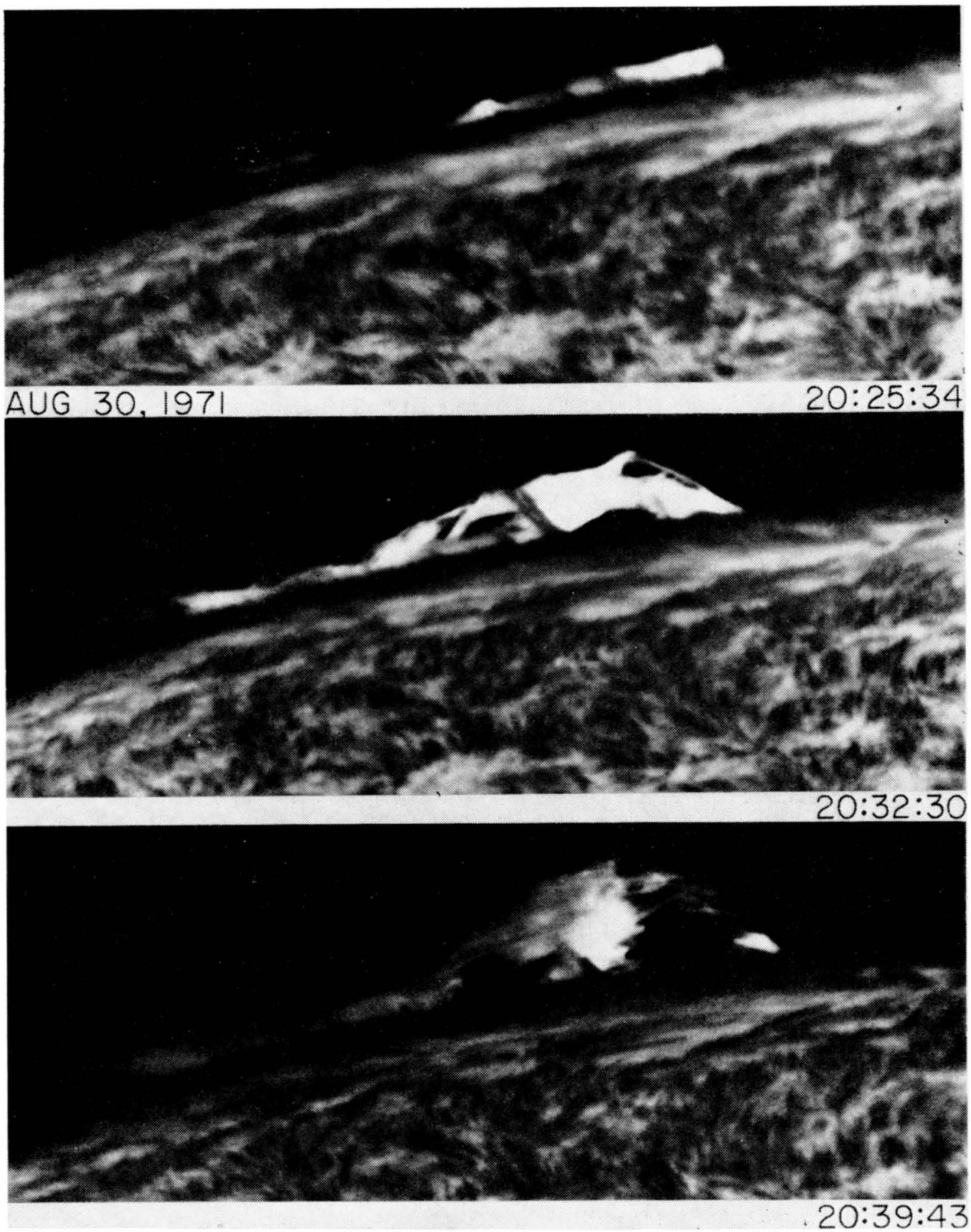

Fig. 8. An eruptive limb flare, August 30.

For this reason, in some parts of the active region we see lower in the K-line, simply because overlying filaments and fibrils do not obscure the view. Note in Figure 4 the bright points between spot (2) and the other spots, obscured in $\mathrm{H} \alpha$ by the tangle of penumbral fibrils. As a result, some low-lying flares are more easily seen in the $\mathrm{K}$-line. Of course, as is well known, plages show up with much higher contrast in $\mathrm{K}$; part of this is because the Planck function is steeper at that wavelength, part is because we see 
higher where there is no overlying material, and, as we noted above, part is because the overlying material, which is dark in $\mathrm{H} \alpha$ is transparent in $\mathrm{K}$. The resolution of our $\mathrm{K}$ picture is inferior to our $\mathrm{H} \alpha$ pictures because of focus difficulties and longer exposure.

\section{Conclusion}

Sunspot motion has often been mentioned as a source of flare energy. We have shown how most of the flares in 11482 on August 19 to 23 appeared directly related to the motion of the $p$ spot of a dipole emerging in the active region, and we have suggested a way in which the different angular rates of motion of the spot relative to far and near field connections produce field line crossings which may be resolved by flares. Whether or not this exact mechanism works, it is clear that something similar is occurring in front of the moving spot. The spot motion in this case is connected with its growth and separation of the $p$ and $f$ portions of an emerging flux region in a preexisting spot, hence the buoyancy of the emerging flux loop is the ultimate energy source.

We found that type III bursts in this center of activity were intimately connected with flares in one location, that flares in other parts of the region gave no type III. Although flares in tightly confined magnetic structures gave no type III, some flares in open structures also gave no type III, so that open field lines or the existence of a concurrent surge are not sufficient for the production of type III emitters. Time comparisons show that the production of type III electrons is simultaneous with the steepest $\mathrm{H} \alpha$ brightness rise. All type III bursts are connected with $\mathrm{H} \alpha$ emission.

Simultaneous K-line observations show no significant difference in the appearance of flares in $\mathrm{Ca} I \mathrm{I}, \mathrm{K}$ and $\mathrm{H} \alpha$.

Much of the activity discussed here is included in the Big Bear 1971 show film.

\section{Acknowledgements}

Dr James Warwick kindly furnished his radio data. This work was supported by NSF under GA 24015 and by NASA under 05-002-071.

\section{References}

Kane, S. and Donnelly, R. F.: 1971, Astrophys. J. 164, 151.

Ramaty, R. and Petrosian, V.: 1972, Astrophys. J. 178, 241.

Severny, A. B.: 1960, Izv. Krymsk. Astrofiz. Obs. 22, 12.

Zirin, H. and Werner, S.: 1967, Solar Phys. 1, 66. 